\title{
A Novel Fading Memory Square Root UKF Algorithm for the High-precision State of Charge Estimation of High-power Lithium-ion Batteries
}

\author{
Weikang Ji, Shunli Wang ${ }^{*}$, Chuanyun Zou, Haotian Shi
}

School of information engineering, Southwest University of science and technology, Mianyang, Sichuan 621010)

*E-mail: $497420789 @$ qq.com

doi: $10.20964 / 2021.07 .68$

Received: 2 March 2021 / Accepted: 8 May 2021 / Published: 31 May 2021

The state-of-charge (SOC) is used to characterize the remaining capacity of power lithium-ion battery. Using the simplicity of Thevenin equivalent circuit model, a bidirectional online improvement model that distinguishes the charging and discharging process is proposed to characterize the state of lithiumion batteries, and the on-line parameter identification of the model is carried out by using the least square method of evolving memory. A novel square root unscented Kalman iterative algorithm based on the dynamic state-of -charge of the lithium battery is designed, and the SOC estimation effect of the combined dynamic estimation algorithm and the unscented Kalman algorithm (UKF) is compared. The dynamic stress test mode (DST) experiment was carried out on the ternary lithium-ion battery at $25^{\circ} \mathrm{C}$. The simulation results show that the average error of the lithium-ion battery SOC estimation of the dynamic joint estimation algorithm and the unscented Kalman algorithm are $1.23 \%$ and $2.11 \%$ respectively. The experimental results show that the joint algorithm based on the square root unscented Kalman algorithm and the fading memory method has better tracking effect, and has higher SOC estimation accuracy and stability.

Keywords: lithium-ion battery; Fading memory algorithm; state of charge; Square Root Unscented Kalman filter algorithm; dynamic stress test.

\section{$\underline{\text { FULL TEXT }}$}

(C) 2021 The Authors. Published by ESG (www.electrochemsci.org). This article is an open access article distributed under the terms and conditions of the Creative Commons Attribution license (http://creativecommons.org/licenses/by/4.0/). 